\title{
Sharing, Households and Sustainable Consumption
}

DOI:

$10.1177 / 1469540516668229$

\section{Document Version}

Accepted author manuscript

Link to publication record in Manchester Research Explorer

\section{Citation for published version (APA):}

Yates, L. (2018). Sharing, Households and Sustainable Consumption. Journal of Consumer Culture, 18(3), 433452. https://doi.org/10.1177/1469540516668229

\section{Published in:}

Journal of Consumer Culture

\section{Citing this paper}

Please note that where the full-text provided on Manchester Research Explorer is the Author Accepted Manuscript or Proof version this may differ from the final Published version. If citing, it is advised that you check and use the publisher's definitive version.

\section{General rights}

Copyright and moral rights for the publications made accessible in the Research Explorer are retained by the authors and/or other copyright owners and it is a condition of accessing publications that users recognise and abide by the legal requirements associated with these rights.

\section{Takedown policy}

If you believe that this document breaches copyright please refer to the University of Manchester's Takedown Procedures [http://man.ac.uk/04Y6Bo] or contact uml.scholarlycommunications@manchester.ac.uk providing relevant details, so we can investigate your claim.

\section{OPEN ACCESS}




\section{Sharing, Households and Sustainable Consumption}

Recently, economists and environmental scientists have problematised households, showing that their reducing size in average number of inhabitants has implications for environmental sustainability due to losses in economies of scale. Findings suggest that resources are shared better when people cohabit. This paper analyses this common domestic consumption, drawing on literature about households, sharing and sustainable consumption. It is argued that multiple person households apportion the resources involved in supplying practices through three modes of sharing: successive sharing, simultaneous sharing and shared/divided work. These are underpinned and enabled by standard material arrangements of households, in which a minimum of certain goods and services are available to residents regardless of number. Exemplifying the perspective, I examine recent survey data relating to meals and domestic laundry, two sociologically significant and resource-intensive spheres of domestic activity, paying attention to differences across one-person and multiple-person households. Modes of sharing, it is argued, also surfeit the domestic sphere, with market, state and household infrastructures playing contextually variable roles in provisioning goods and services among populations.

Keywords: modes of sharing, households, solo living, sustainable consumption, economies of scale, eating patterns, laundry, sharing economy, collaborative consumption, common material arrangements 


\section{Introduction}

The term household refers to those people who have common use of an address, sharing some space and practices. Yet, types and degrees of sharing vary considerably across domestic settings, in part because larger size affords greater possibilities for common access to goods, co-performance of practices and divisions of labour. These mechanisms mean that declines in the numbers of people living together and increased solo living fundamentally affect domestic life and domestic resource consumption. Larger households appear to share resources more effectively, but the dynamics of common use in daily life which make it so have not been explored or theorised.

This is the departure point of this article, which investigates households and resource consumption through analysing economies of sharing: the ways in which people consume resources in common. It begins by outlining relevant literature in two main areas: households and the domestic - especially one-person households - alongside work about sharing. Domestic economies of scale are typologised, taking place through three modes of sharing, successive sharing, simultaneous sharing and shared/divided work. These are enabled by standard common material arrangements, contemporary private households being spaces equipped with a standard set of goods. The second section introduces two domains of domestic practice: eating patterns and laundry habits, for illustrating dimensions of sharing in different types of household. It draws on British quantitative survey data and selectively employs broader contextual and secondary literature to do so. Section three reviews findings and their implications for sharing within and outside of households, suggests some key dynamics of change in economies of sharing, and makes suggestions for further research.

\section{Households and consumption}

Debates about the decline of family structures, community life and rise of individualisation dominate popular and academic accounts of recent social change. Among the more compelling evidence may be the global transition towards smaller households. The average number of people living in the same address has been diminishing for a large majority of the world's countries since 1950 (Mackellar et al 1995). Around a third of households in North America, Europe, and Japan are now of only one person, and trends are forecasted to continue (Jamieson and Simpson 2013: 34). Smaller households are associated with economic development and rising affluence, changing family structures, longer life expectancies and increased mobility (Hall et al 1997, Williams 2007). Social implications are far-reaching, yet the household form itself has historically been granted little direct analytical attention. The phenomenon of one-person households is beginning to come under increasing sociological scrutiny alongside increased attention to 'alternative', that is to say 'communal' or non-familial, living arrangements.

In the social scientific study of living alone, a number of well-rehearsed debates and controversies dominate discussions, filtering into accounts of the consumption of different household types. Jamieson and Simpson (2013) argue that solos are dichotomised by popular culture into familiar stereotypes: the young, affluent, profligate singleton, and its counterpart the elderly, socially vulnerable widow or widower. Popular representations and some academic work presents a similar 
bifurcation, between solos with or without agency - specifically those supposed to have elected to live alone, and those forced to do so (Bennett and Dixon 2006). The distinctions resonate with how living arrangements such as lodgings, boarding houses and bedsits have been popularly understood, where residents are often portrayed as either suspiciously agentic, or as objects of pity and concern (Heath and Cleaver 2004, Klinenberg 2012). The rise of living alone provokes long-standing fears concerning individualisation, recurrently predicted, confirmed and lamented since Durkheim and Tönnies. Much representation of solo living indicates continuing preoccupation about deviation from 'normal' households or families and certain communal and sociable practices, threatening community, civil society and traditional values. Where one person households are considered environmentally problematic they may draw on influential normative discourses about how to live.

Extant studies provide empirical clues about the composition and daily life of differently sized households, yet comparison has been limited to rudimentary social indicators and expenditure figures. Research can be roughly divided in two. Quantitative work compares different kinds of households, providing useful socio-demographic data about how solos differ from other households in terms of the characteristics of inhabitants (e.g. Hall et al 1997, Smith et al 2005). Further insights are gleaned from analysis of expenditure data to identify dynamics of household energy use and 'metabolism', comparing across key consumption categories and types of households (e.g. Moll et al 2005). Most striking in the analysis of solo living is the degree of polarisation across different age cohorts and gender (younger solos are disproportionately male, older solos female) and a clustering in both the poorest and most affluent income percentiles (Williams 2007), and affluence and age in turn are major factors explaining differences in resource use. Solos are also more likely to rent, live in cities or coasts, and be suffering from long-term illness (Hall et al 1997, Smith et al 2005). A second, mainly qualitative, literature explores the experiences and practices of living alone (Klinenberg 2012, Heath and Cleaver 2004, Molgat and Vézina 2008, Jamieson and Simpson 2013). These accounts, though alert to the advantages and freedoms that single life and living alone may engender (Klinenberg 2012), above all render a sense of the practical and normative constraints on living alone. Jamieson and Simpson's (2013) narratives about solos' food consumption, and around holidays and Christmas, relate challenges that are both logistical, particularly in the case of eating alone, and emotional, in that a great many practices around leisure and the domestic are loaded with cultural meanings around family. The advantages of solo living, including the expansion of choice and independence, seem transient: Molgat and Vézina's (2008) interviewees represent solo living as either a temporary youth lifestyle about choice and friendship, as a period of transition towards conjugality, or an undesirable and lonely long-term scenario (see also Heath and Cleaver 2004). In terms of consumption, insights are scant in the first literature simply because of the breadth and type of analysis, which analyses broad trends and outcomes rather than mechanisms underpinning them, while qualitative studies render key dynamics of daily life, touching only implicitly on matters of sharing or resource consumption.

Work on 'alternative' living arrangements, including for example house-shares, communes, cooperatives, halls of residence and co-housing, explores the sharing of space, time and resources more directly (e.g. Heath and Cleaver 2004, Jarvis 2015, Yates 2015). Such projects challenge moral norms about households, sharing and family, often more deliberately than solos, drawing academic attention precisely for how sharing and communality are practised. Most studies show that residents 
also encounter various difficulties and contradictions in negotiating common and personal possessions, space and time. Much private property, personal space and 'alone time' is retained by individual residents in these arrangements, demonstrating that the economies of scale achievable in larger households are only ever partially realised. This work describes the tensions and satisfactions involved in sharing. However, they tend not to compare how participants in other kinds of household - couples, nuclear families, single parent families or other arrangements - divide and share their time, labour and resources.

The core sociological question of how social interaction differs historically and across residential type is given new urgency, in normative and policy terms, by concerns about the environmental consequences of recent change. As larger households consume fewer resources per person due to economies of scale, shrinking households have been named among the major problems facing climate change mitigation efforts (Liu et al 2003, Williams 2007). Smaller households, holding all else constant, increase (direct and indirect) energy and resource consumption, domestic waste, production of CO2, and biodiversity losses across a range of national contexts (MacKellar et al 1995, Liu et al 2003, Moll et al 2005). The mechanics are presumed to be simple: one-person households cannot benefit from the efficiencies of 'normal' (presumed to be nuclear family) household economies of scale where several people supposedly share space, domestic upkeep, meals and forms of entertainment, particularly significant with regard to direct energy consumption. Smaller households are regarded as inefficient distribution of people who could otherwise live together as families or as small communities (Williams 2007, Jarvis 2015). In this literature, daily life in small or one-person households is presumed to be qualitatively similar as life in larger or nuclear family households, but is quantitatively different; people living alone do, own, make and consume resourceintensive things alone rather than together. Yet, the extent to which this holds is an empirical question, and the dynamics of common use in daily life which presumably make it so have not been explored or theorised. ${ }^{1}$

Much is at stake in households and the household mode of provision. Living arrangements are loaded with moral associations, such that satisfactory performances of many practices appear contingent on co-residency. Varying degrees of economies of scale make small households more resource-intensive, cost-intensive and labour-intensive per person, with implications for the environment and the inhabitants' experiences of daily life. The singularity of solos and non-familial living arrangements is thrown into relief through comparisons that often presuppose nuclear families as normal despite the latter's minority status. Yet it seems unlikely that households of couples or families with children reliably share everything that they consume, or spend all their time together performing the same practices that solos do on their own. It is worth turning here to review the literature of sharing and collective forms of consumption, which allow a set of theoretical categories for analysing common resource use to be developed.

\section{Economies of sharing}

\footnotetext{
${ }^{1}$ An interesting and recent exception, published since submission, develops an approach to these questions using concepts from time-geography and raw time-diary data to examine consumption in Swedish households (Isaksson and Ellegård 2015).
} 
Literature relevant to sharing emerges from diffuse social scientific traditions. John Price (1975) proposes a simple definition, 'a general term for common use or distribution' (4). Dictionaries offer numerous senses, including 'to divide and apportion in shares between two or more recipients', 'to receive, possess, or occupy together with others', and 'to perform, enjoy, or suffer in common with others' (OED 2015). Accordingly, perhaps, the term's deployment varies substantially by a function of where sharing is understood to take place, what is being shared, and among whom shared goods are allocated. A range of types and uses for 'sharing' can be identified which hold value for studying scale differences and changes in domestic resource use.

Sharing is frequently distinguished from other economic forms as being particular to the home, family or small community. Price's intuitive premise is that economic forms are ranged according to social and geographical distance. Sharing is thus presented as intrinsic to the intimate sector; contrasting with reciprocity, understood as a form of exchange and involving calculation of returns as in communities and markets; and redistribution, which is similar to sharing, but occurs through centralised means such as in the public sector (condensing Polanyi's distinction between reciprocity, market exchange and redistribution). Russell Belk's (2010) work continues in a similar vein, theorising familial sharing - specifically mothering, and the pooling and allocation of resources within the (presumed co-resident) family - as prototypical sharing (717), such that one should deduce whether sharing is taking place through the case's resemblance to family practices. It poses this intimate sharing as involving the use of joint possessions such as food, money and space. The commensal sharing of meals with family is an archetypical case. Stephen Gudeman (2001) uses the term more broadly to refer simply to the mode in which 'commons' are distributed among a population or 'community'. 'Sharing' in most examples, nevertheless, does not involve any obvious exchange or pecuniary benefits and it involves co-presence and co-participation depending on joint access to or ownership of possessions.

Empirical studies of the allocation of resources in households, meanwhile, reveal how domestic labour and expenditure is divided and distributed. Analysis of the domestic division of labour shows a slow trend across many national contexts towards more equal 'sharing' or distribution of domestic work (Kan et al 2011). Much work has followed Jan Pahl's (1990) study of married couples' expenditure, showing how much shopping is carried out on behalf of the family by women - the point highlights that in most shared dwellings work is carried out for co-habitants - who share the utility of this work without having to do everything they need themselves. This co-dependence is extended in the work of Miriam Glucksmann (2014), who describes how shifts in one sphere or mode of provision affect divisions of labour in another, using the example of ready-made food to show how preparation can take place in factories up-stream, potentially shifting labour out of the household. The distribution of labour and expenditure in households is dependent on internal dynamics but also labour and spending taking place outside them. In all these cases, the 'sharing' undertaken is of responsibilities, labour and the fruits of divided or shared work.

Contemporary literature about 'collaborative consumption', 'access-based consumption' and the 'sharing economy' (Botsman and Rogers 2010, Bardhi and Eckhart 2012, Belk 2014, Schor and Fitzmaurice 2015) moves further still from anthropological definitions of sharing. It is preoccupied 
much less with family relations and their allocation of spending, food and labour. Rather, this work focuses on novel relations of ownership for market- and community-provisioned goods and services, with the 'sharing' of utility generally in the form of successive access for which an owner usually receives monetary recompense (Cohen, forthcoming). The terms are used to refer to a constellation of arrangements and business models including the peer-to-peer property rental scheme Airbnb, short-term car hire firms exemplified by Zipcar, freelancing work schemes such as Uber, cycle pooling or rental setups, internet file-sharing, and community exchange vehicles such as Freecycle (Botsman and Rogers 2010). The novelty distinguishing collaborative consumption or the 'sharing economy' from other collective forms is that these sharing arrangements tend to be mediated by the internet and new digital technologies, often through 'peer-to-peer' networks, although the forms of mediation and the relations between 'peers' vary case by case.

The potential for greater sustainability through scale savings is vaguely but repeatedly referenced on the basis that goods get used more intensively and by more people than is considered normal for most commodities privately owned by individuals. Bardhi and Eckart (2012) focus on precisely this distinction in their article on 'access-based consumption', contrasting it with an 'ownership model', as does Belk (2014). The potential shift from ownership to access, it is suggested, engenders more sustainable forms of consumption, while stimulating new forms of reciprocity and community through its decentralised nature. Yet this optimism depends on an ahistorical perspective of scale and consumption (Cohen, forthcoming). Models of common use, supply and consumption already in operation that are not internet-mediated and novel are ignored. There is no mention of collective ownership or collective consumption such as that of the state and market (see Warde 1992), how goods and services have replaced one another in the past (see Gershuny 1978), or of the politics of renting and owning. Many services in the public and private sector already involve the servicing of many more people than if every individual personally owned the goods necessary to enjoy the same experience. The sustainability credentials of sharing economy innovations are suspect.

Belk points out that sharing in households depends on joint possessions, allowing joint or shared access: similarly the 'sharing economy' proposes that access rather than ownership is critical, allowing sharing to mean turn-taking, successively shared use, irrespective of whether access costs money. The notion of 'shared access' here is qualified neither by its taking place in the family sphere nor its being non-pecuniary, but by an improved economy of scale. While controversial, and clearly in breach of Belk's and most anthropologists' definitions, it fits Price's broad determination and, I will argue, is also of use for considering the processes which allow differences in household size to result in differing economies of scale in resource consumption.

\section{Domestic economies of scale: Modes of sharing and standard material arrangements}

In order to theorise the processes which allow larger households to be less resource intensive, economies of household provision can be schematised following the literatures about sharing, and based on empirical case studies of mundane domestic activities. Larger households are less resource intensive than small households because they are able to engage in a combination of three generic modes of resource sharing: simultaneous sharing, successive sharing, and shared or divided work. These modes of sharing are made possible, and each may result in improved resource efficiency 
when compared to one person households, because households have standard material arrangements - a form of commons which varies surprisingly little despite numbers of inhabitants. The schema is described below, and deployed in making sense of the empirical case studies of the next section.

Western households customarily have a minimum of basic material infrastructures which varies little by the characteristics of inhabitants or of how many people live together at the address. ${ }^{2}$ A vast majority of private households in the UK, irrespective of size and numbers of inhabitants, have refrigerators, cookers, washing machines, and a certain amount of potentially lit or heated designated space in the form of kitchens, bedrooms, bathrooms, living rooms and so forth. These standard material arrangements are presupposed and prefigured through norms which shape what is possible and likely to take place in them, ranging from the legal (tax arrangements) to infrastructural (plumbing, energy, telecommunications) to cultural conventions (around for example privacy, selfsufficiency and shared utility). Household co-residents have common access - usually through the mechanism of joint ownership described by Belk (2010) or based on an access-type relationship (Bardhi and Eckhart 2010) for many of those that rent - to standard material arrangements of domestic space and objects. This access is enjoyed through a combination of modes of resource sharing.

These overlapping dimensions of common resource use, also based on literature about sharing, schematise the distribution of goods and resources in multiple person households. They generally operate in combination in any sphere of activity or episode of consumption. First, and as a minimum, even if co-residents spend very little time together such as in contemporary house-shares, they successively share the household, availing themselves of the same kitchen facilities, public areas, etc (a mechanism similar in form to the successive access described in the arrangements of many examples from the sharing economy). Even if householders' schedules do not correspond and they never see one another, their access to the same space means that capital goods and space are likely to be used more intensively than a single person household, in which a single person, perhaps occasionally with guests, makes use of the very similar infrastructure that a household is expected to have. Secondly, and to a varying degree, one can simultaneously share amenities in multiple person households. In simultaneous sharing household space and appliances and the energy and water they require are used in common concurrently - more similar to the sharing described by writers such as Price (1975) and Belk (2010). Examples might include the shared consumption of meals; of entertainment such as that around TVs, music or computing devices, the shared occupation of heated or air conditioned, lit space, and the pooling of washing machine loads among household members. The third, final and again overlapping mode of common resource use refers to sharing and dividing work, involving labour such as care; cleaning; food preparation; maintenance, gardening and DIY; and shopping (the forms of sharing described in work on household expenditure and domestic division of labour). Such housework is shared or divided and its utility enjoyed in common among household members.

\footnotetext{
${ }^{2}$ This is not to disregard the substantial inequalities in housing, consumption or energy use in most contexts, whose consequences are more environmentally significant than differences in household sharing (see Williams 2007, Yates 2016).
} 
Many episodes of household consumption involve all three modes of resource sharing in multiple person households, as the empirical sections below illustrate. The organisation and production of a meal may involve successive purchasing and storage of ingredients by one household member, their preparation by another, simultaneous commensal consumption by most of the household simultaneously, in the same heated or cooled space, who all share the benefit of this divided work and material arrangements, potentially followed by further successive meals based on left-overs by absent others. While such forms of organisation may be typical in large households, possibilities are reduced in smaller households despite many of the material arrangements and the resources necessary to produce a single meal being the same. Solos, more often than not, purchase, prepare and eat meals alone (see below). They may entertain, cook in bulk, involve others, paid or unpaid in these practices, but generally speaking sharing options are restricted because of the household form institutes certain arrangements where goods and services are ordinarily shared within, but not between, domestic units. Recognising that standard material arrangements, and three different types of sharing, underpin household economies of scale, helps unpick the assumption that consumption differences are caused by people simply doing more resource-intensive things together. Different modes of sharing are typical in different social contexts and relationships: simultaneous sharing is typically sociable, intimate and communal, whereas successive sharing and the sharing and dividing of work may have similar environmental implications but do not rely on being and doing things together with others, suggesting relations that include care, service, exchange, anonymity and hierarchy. This means that variation in household types, ranging from adult-only, to single parents with dependent children, to a mix of adults and semi-autonomous teenagers, to house-shares of people who hardly know one another, engender different combinations of modes of sharing which help explain substantial differences in resource consumption. ${ }^{3}$

A final important point concerns the modes of sharing and standard material arrangements of institutions and economic bases other than the household. Cities, social institutions and businesses have different standard material arrangements, which in turn presuppose different patterns of successive sharing, simultaneous sharing and shared/divided labour, and which are similarly consequential in terms of resources. Just like with households, certain material arrangements shape similar modes of sharing as those of the household - the choreographies of successive turn-taking, simultaneous use and divided labour evident in hospitals, schools, offices, shopping infrastructure, leisure facilities, and so on. Some implications of this, especially relating to the household, will be discussed in the discussion and conclusion.

The next sections of this article look at shared and lone domestic consumption practices across different types of households, to exemplify the schema and better account for differences in their resource intensity. By way of illustration, two spheres of activity - meal patterns and domestic laundry - both of which have been considered sociologically and ecologically significant by prior work, are analysed using survey data collected in 2012 and 2013 (see Yates and Warde 2015, Yates

\footnotetext{
${ }^{3}$ It is not possible to satisfactorily approximate potential reductions in resource intensity through each generic economy of sharing without comparisons based on life cycle evaluation of the environmental impacts of activities, which can however instructively be combined with time use and expenditure data (e.g. Heinonen et al 2013).
} 
and Evans 2016). Comparisons are drawn between individual and household performances, and between different types of household.

\section{Two illustrations: Shared meals and domestic laundry}

\section{Data and Methods}

Both surveys sampled from a self-selected panel of supermarket loyalty card holders - British adults aged over 18 - in exchange for card 'points' to be redeemed against the value of goods. The first was conducted online in 2012. It asked respondents to report on eating episodes taken in the day prior to the questionnaire and for one day of the previous weekend, including what they ate on each occasion, where they ate it, when, where it was obtained, how it was prepared, with whom they ate it, and for how long. Demographic and socio-economic variables were gathered and the sample size was 2784 individuals or 14831 'main meals'. The second survey, administered to the same base panel, was carried out during February 2013, on the subject of domestic laundry practices. The questionnaire requested detailed information about how households carry out their laundry in terms of what equipment and products they owned, how they organised and distributed the various tasks associated with laundering, the timings and stated reasons why they do the laundry at particular junctures and in certain ways, and respondents' definitions or associations with dirt and cleanliness. The sample size was 1502 individuals. Each questionnaire took around 15-20 minutes to complete. As self-selecting members of a consumer panel neither sample should be considered representative of the British population. The sample for the survey on eating patterns was also skewed towards older, more affluent, better-educated respondents and those without children, while the laundry survey contained more households without children than would be representative.Claims presented have been checked in the light of these differences. Notwithstanding these limitations, the data are copious, recent and appropriately detailed. 
On a number of counts, eating patterns and laundry practices are propitious spheres of activity to analyse for unpacking the social and material dynamics of household sharing. Social science has long identified them as pivotal in reproducing social relations of the family (e.g. Kaufmann 1998, DeVault 1991). Their history already demonstrates complex trajectories of state, market and household provision which illustrate the types of resource sharing that can take place inand outside of the household in daily consumption practices. Eating patterns and laundry practices are also not only of significant political weight in the highly gendered work of domestic social reproduction, but have also featured in alternative living arrangements, where more communal ways of organising displace 'normal' household ways of life (Jarvis 2015, Yates 2015). The analysis that follows, however, is not presented as an intervention into the state of knowledge in either practice, but as an illustration across two different areas of activity of how modes of sharing work in practice, and thus how economies of scale in households are composed.

\section{'Dirty Linen': economies of scale in domestic laundry practices}

The environmental consequences of laundry are significant and are escalating globally. In the UK, domestic laundry accounts for an average of $12 \%$ of energy, and $13 \%$ of the water used in private households (Yates and Evans 2016). Increasing numbers of wash cycles (284 cycles per household per year in 2012, up from 274 in 1998, the corresponding figure for the USA is 392, suggesting numbers could rise indefinitely), and a slow increase in washing machines, washer-dryers and tumble dryers have contributed towards doubling the energy used by domestic laundry since 1970 (ibid). Cleaning clothes in the global South is often reliant on different, often communal arrangements which are rapidly becoming displaced by the private washing machine and tumble dryer. Washing machine ownership ranges from 20 to 95\% in Latin America, averages 59\% in Asia Pacific, and 50\% in Africa, with tumble dryer possession 7\%, 4\% and 7\% respectively - year-onyear growth is most rapid in the BRIC economies (Euromonitor 2015).

The way clothes are washed and dried in the UK is currently heavily dependent on particular appliances that are allocated per-household (for earlier provisioning arrangements see Watson 2014). Overwhelmingly, households have their own washing machines $(85 \%)$ or washer-dryers $(12 \%)$ and half $(51 \%)$ have tumble-dryers. Most respondents with washer-dryers and tumble-dryers also have clothes horses and washing lines - tumble drying has no monopoly in the plurality of infrastructures including radiator and dehumidifier drying, outdoor line- or rotary driers, and indoor 'horses'. Solos have disproportionately few tumble-dryers (32\% compared with $55 \%$ of multiple-person households) and comparatively more washer-dryers (19\%, in contrast with $13 \%$ of multiple-person households). The additional expense of a tumble dryer, allied to - it may be assumed - space constraints, likely account for the differences, similar to the lower ownership rate of cars among solos. Overwhelmingly, a standard household material arrangement of one washing machine per address applies irrespective of numbers of residents, while ownership of tumble driers is more contingent on household size, affluence, age and other factors. Washing infrastructures are reliably shared within (and apparently almost never across) households. 
Depending on the relationship between residents, the modes of sharing at play vary: there is often simultaneous as well as successive sharing in multiple-person households, and the work involved is clearly divided labour. Detailed data on household electricity use indicates that the pooling of laundry loads among household members (a form of simultaneous sharing) means that smaller households also require many more washes per person (EST/DEFRA/DECC 2012). Single person households, in fact, run more wash cycles per person than do households with children, and in similar numbers to households of two people (ibid). Eighty-three per cent of shared households say that 'all laundry is done together', with the remainder divided among alternative arrangements ('all household members do their laundry individually' - three per cent, 'some laundry done as household, some individually' eleven per cent and 'some members of the household do their laundry together, others do not' accounting for three per cent). Households of only adults (couples and other configurations) are marginally less likely to pool their washing (82\% compared with $86 \%$ ). Among adult-only households, respondents who are unmarried are least likely to wash their clothing with all other household members, $61 \%$ of households of two unmarried adults pool, and only $42 \%$ of those composed of three adults or more. Residents of multiple person households who do not pool or simultaneously share their laundry do not have their own personal washing machines; hence, they still engage in successive sharing. The tasks of laundry, involving using the machine, sorting and separating, drying and putting items away, are not carried out by every member of the household but tends to be divided work, generally with low participation from men (Yates and Evans 2016).

A set of observations are worth retaining for reflection. Nearly every household has one washing machine despite large variation in numbers of inhabitants: these are the minimum material arrangements which lead to small households doing more washes per person than larger households. A counter-trend is that those living alone are less likely to own tumble-dryers, which are very resource-intensive: some appliances are less likely to come as standard in all households. The sharing of this infrastructure is dependent on the boundaries of the household. Within households there is some variability in how laundry is done, with most households pooling the washing of all members together - simultaneous rather than successive sharing, with the labour involved also shared or divided.

\section{Eating alone and with others: economies of scale in domestic food consumption}

The food system overall has been estimated as accounting for 20-30\% of global greenhouse gas emissions, across the loosely demarcated spheres of production, distribution and consumption (Bows et al 2012). Increased commercial eating out (Warde and Martens 2000) and a continued role of institutional catering (for schools, workplace refectories, prisons etc.) mean that several modes of provision supply the population with meals, varying the material arrangements and modes of sharing possible. Globalisation processes, and popularity of a vast repertoire of pre-prepared and convenience products also mean that moments of production and consumption are variably distributed across supply chains and 'consumers'. I examine several areas concerning shared 'enduse' food consumption: co-presence at meals (the degree of simultaneous rather than successive sharing), and the origin and preparation of meals (including whether they are home-prepared, how they are prepared, and how many people prepare them - a form of shared/divided labour) - with comparisons across one-person and multiple-person households foregrounded. 
In the UK the practices around feeding a household are subject to similar modes of sharing to laundry, benefiting from a minimum standard material arrangement that comes with the address (kitchen space usually with refrigeration and cooking facilities). Surveys of electricity use show that cooking is another major area where small households on average use much more energy per person than large households (EST/DEFRA/DECC 2012). This suggests that people who live alone eat alone more, such that co-residency is both the main factor predicting sharing of meals and the energy invested in their preparation. The data show that people who live alone, as suggested by the literature, indeed do eat alone much more often, for $74 \%$ of their meals, compared with $27 \%$ of the meals eaten by respondents from multiple-person households. This appears to be because companionship at meals (a form of simultaneous sharing) is dominated by co-residency. For those living with others, just under half of meals on weekdays (46\%), and around two-thirds on weekends (65\%), are eaten with household members. The next most common arrangement in each case is eating alone, happening at four in ten weekday, and one in five weekend, meals. Although patterns of commensality show that the normal companion at meals is the co-resident; people living alone do not always eat alone, and people living with others do not always simultaneously share their meals.

Table 1 compares the meals of one-person households with those of respondents in shared households by origin (where meals are prepared) and preparation (how meals coming directly from home are prepared), with further distinction made between the lone and shared meals of each. One-person households eat with others much less frequently (entailing more resource-intensive food preparation overall), but when they do so they are more likely to eat out - meals originating from restaurants, takeaways, workplaces or friends and family in over one-third (44\%) of cases, compared with only one-sixth $(16 \%)$ of the shared meals of people living with co-residents (implying reduction in resource intensity). The sharing of meals is a domestic affair for people living with others, whereas meals shared by solos are prepared outside the home. All such meals that are simultaneously shared outside of the household may make use of commercial material arrangements that involve larger numbers of people eating together (simultaneously 'consuming' the meal and the lit, climate controlled space) and more complex and scaled divided work (the professionalised roles of the restaurant). Meanwhile, lone meals - much more common for solos - are similarly provisioned for all household types, with four out of five (83-86\%) being derived from household food stocks.

Examining the preparation of this subset of meals that originates from the household food stocks (also see Table 1) shows further variety depending on household type and whether meals are eaten alone or with company. Lone meals of people who live with others are much more likely to require little or no cooking (84\%) than are the lone meals of solos $(63 \%)$. Variation in the practices of preparing food in this case suggest that solos' lone meals are more resource intensive than lone meals by people who live with others, in addition to solos not being able to share resources to the degree that shared households can.

Table 1: Origin and preparation of shared and lone meals for respondents living in one person and shared households (percentages) 


\begin{tabular}{|c|c|c|c|c|c|}
\hline & $\begin{array}{l}\text { Shared meal } \\
(27 \%)\end{array}$ & $\begin{array}{l}\text { Lone meal } \\
(73 \%)\end{array}$ & $\begin{array}{l}\text { Shared meal } \\
(76.5 \%)\end{array}$ & $\begin{array}{l}\text { Lone meal } \\
(23.5 \%)\end{array}$ & \\
\hline \multicolumn{6}{|l|}{ Origin/preparation } \\
\hline $\begin{array}{l}\text { Meal from home (home } \\
\text { prepared) }\end{array}$ & 56.0 & 83.4 & 80.4 & 85.7 & 80.1 \\
\hline $\begin{array}{l}\text { Meal prepared } \\
\text { elsewhere* }\end{array}$ & 44.0 & 16.6 & 19.6 & 14.3 & 19.9 \\
\hline \multicolumn{6}{|l|}{ Preparation (meals from } \\
\hline \multicolumn{6}{|l|}{ home) } \\
\hline Ready to eat/warmed $* *$ & 51.5 & 63.3 & 46.1 & 84.0 & 56.2 \\
\hline Cooked $* * *$ & 48.5 & 36.7 & 53.9 & 16.0 & 43.8 \\
\hline \multicolumn{6}{|l|}{$N($ meals $)$} \\
\hline Origin & 604 & 1633 & 9428 & 2904 & 14829 \\
\hline Preparation & 332 & 1304 & 7478 & 2425 & 11753 \\
\hline
\end{tabular}

* Direct from shop, restaurants, takeaways, work, friends/family, other, combination

**Use of toaster, microwave or both, but not oven or hob

*** Use of oven or hob involved

Lastly, moral norms tend to favour commensality, the shared eating of meals, and people generally report preferring eating together (e.g. Jamieson and Simpson 2013), leading to greater social scientific interest in shared meals than in their preparation. Yet it is partly the economies of meal preparation and divided work servicing multiple, usually simultaneously shared meals that gives the arrangement significance in terms of resources used. For the meals of households that are eaten in company and come from household food stocks, so are prepared or assembled at home, 94 per cent are reported as being made by one person (from which 76\%, respondents claim, are they themselves).

In sum, examining eating patterns is useful for exemplifying modes of sharing in households. First, comparing between households shows that eating alone, while more common, is not exclusively the preserve of one-person households. Multiple person households do not always simultaneously share - a quarter of their meals (24\%) are eaten without others present. Secondly, lone meals are significantly different in their origin and preparation to shared meals. Overall, one in five (20\%) meals are prepared outside the household, where modes of sharing allow food preparation and distribution to benefit from commercial material arrangements of restaurants, workplaces, caterers and retailers. Lone meals and simultaneously shared meals are also different between one-person households and shared households - one-person households are more than twice as likely to get their simultaneously shared meals from outside the home, but are at the same time twice as likely to cook their home-originating meals using the oven or hob. Lastly, it is overwhelmingly the norm for simultaneously shared meals in multiple residency households to be made by one person. The 
preparation of one meal serves potentially many household members 'sharing' the same food, cooking and benefiting from the preparatory divided labour done by usually one member.

\section{Discussion and conclusion}

\section{Patterns and ambivalences in domestic resource sharing}

Forms of common provision which reduce resource intensity per person in larger households are empirically identifiable in meal patterns and laundry practices, and are apparent in many other spheres. Standard material arrangements in households, including the one-per-household norm of most appliances such as washing machines or spaces such as kitchens and living rooms means the ratio of material infrastructure to people is higher in households with fewer residents, leading to opportunities for efficiency savings of three kinds. Smaller households have fewer opportunities to simultaneously share their domestic activities - meals, entertainment, laundry loads etc. They are also less able to successively share the infrastructures of the household - using the same washing machines, cookers, kitchens, living rooms and eating the same meals at different times. Residents of one-person households, thirdly, cannot reduce their 'share' of the resource-intensive performances of domestic production through shared and divided labour as is usual with meal preparation, cleaning or doing the laundry.

Ambivalences and counter-trends, specific to practices, should be borne in mind. These complement recent sociological research on living arrangements (Klinenberg 2012, Jamieson and Simpson 2013). People living alone do not spend their lives entirely alone, and those in shared households do not share resources in the same way or in all domestic practices. Although meals in one person households are three times more likely to be eaten alone than meals in multiple-person households, a quarter of meals in the latter are still eaten solo. One-person households tend to eschew hugely energy inefficient tumble-dryers (as they do cars), showing that the standard material arrangements of the vast majority are minimums which do not foreclose variation by socio-economic circumstances, different rates of adoption for innovations, etc. Furthermore, several broader countervailing factors to household sharing effects should be borne in mind: household economies of scale may be insignificant when taking the size, quality, tenure-type and location of dwellings and the social position of residents into account, and diachronic perspectives of consumption illuminate differences that analyses of expenditure occlude (Yates 2016). Household scale effects are important for explaining variation in resource intensity, but subtend a range of other trends and factors.

\section{Sites and modes of provisioning: interdependency, hybridity and creative destruction}

Households are only one site in which such economies around sharing are important, underlining that there are different types of 'sharing', many of which do not correspond to family relationships and joint ownership (Price 1975, Belk 2010). Sharing as examined here is also about relationships of unequally divided work (divisions of expenditure and labour) and unequal relationships around the control and ownership of goods and services (as in the 'sharing economy'), each of which are even more visible outside of the domestic sphere. The goods and services available in households, and the 
things considered normal to produce and consume in them, are interdependent with what is provided by the state, market and the community (Warde 1992, Glucksmann 2014). A household may not need a car if there is excellent public transport available; public parks and allotments have compensate small gardens; schools allow parents to pursue work outside of the home; pubs and restaurants are alternative places to the home to supply meals and drinks; leisure facilities offer competing alternatives to home entertainment. In these contexts, where states, markets and communities provision goods and services; there are different minimum standard material arrangements to those of the household - of workplaces, institutions, neighbourhoods, cities and countries - and different patterning of modes of sharing. These have similar environmental implications to the variation in economies of scale attributable to household size differences. The way these arrangements and modes of sharing are patterned determines the extent to which innovations in the sharing economy hold value for sustainable transitions or not. ${ }^{4}$ Different practices are provisioned at different sites, so modes of sharing in households vary, becoming more or less important with respect to what is available outside them.

The interdependency between modes of provision reveals some coexisting and competing systems, and some layering and hybridity among different sites (markets or states may provide services directly, as with restaurants, or goods that allow households to service themselves, as with ingredients, cookers and fridge-freezers). There are also historical trends in practices from one mode of provision to another, encompassing changes in the economies of sharing, resembling creative destruction. Jay Gershuny's (1978) example of the 'self-service economy' describes a trend towards replacement of goods for services which shift production to the household; however, commodities and practices reveal a range of trajectories implicating the way practices are ordinarily done and their environmental consequences that further research could illuminate. Change in economies of sharing is not unidirectional, but several key dynamics appear to drive escalation in the resource intensity of everyday life, operating in conjunction with declining household size. One such dynamic is the reduction of economies of sharing from public to domestic. This appears to increase ratios of standard material arrangements to people, as with the transition from launderettes, shared taps and laundry services to washing machines; and diminishes opportunities for simultaneous sharing as in the development of home entertainment ${ }^{5}$. Eating out appears an unusual but significant qualification to this dynamic, entailing a move from the household and the family meal to meals provided by

\footnotetext{
${ }^{4}$ Arguments about collaborative consumption, sharing economies and product-service systems are for the most part concerned only with a subset of such arrangements, those which attempt to increase the number of uses, or lifetime, of privately owned capital goods - predominantly some version of successive sharing. Compared with a hypothetical scenario of standard arrangements in which everybody in a population owns several properties, is always travelling, or needs their car very infrequently but nonetheless owns at least one, these activities may appear an improved allocation of resources. Yet the advantages of such resource sharing are limited compared to the arrangements and modes of sharing obvious in the much older models of sharing evident in public transportation, local cinemas and libraries. If the environmental consequences of economies of scale and of sharing are to be realised, the public mode of provision, and forms of collective consumption must be part of the 'sharing economy' debate.
}

\footnotetext{
${ }^{5}$ The development of soft furnishings and home entertainment coincided with a decline in the popularity of cinemas (Docherty et al 1987), helping shift the standard material arrangements and degrees of simultaneous sharing in the entertainment of mass audiences.
} 
private catering, normally for larger groups than would share a household (Warde and Martens 2000), and the market also does more of the preparatory work for home-produced meals (Glucksmann 2014), producing greater hybridity between provision forms. Processes of further personalisation extend the process of domestication of services and goods by allocating them per-person (as with telephones, televisions, cars, computers and bathrooms) or per-room (television, heating sources and electricity points) rather than per household, or from one per room to many per room (lightbulbs). More research could profitably examine the dynamics that characterise the relationship between practices and technologies with greater/renewed attention to the variation in material flows consequential to changes in economies of sharing.

\section{Beyond common resource use: the sharing of space, time and practices}

The implications of household size changing evidently go far beyond the environmental, and the processes analysed as resource sharing are sociologically charged. A meal with others is qualitatively distinct to one taken alone, furthering wholly different projects and meanings, and both categories encompass enormous further variation. The divisions of labour around laundry are not reducible to questions of ratios and matters of scale. Few of these matters could be explored in the present paper, yet they must be brought back together with questions of resource sharing for understanding of scale in sustainable consumption to be further developed. The social dynamics of simultaneous sharing and household distributions of work are relatively well understood; compared to successive sharing (the closest to sharing economy), which concerns the politically freighted matters of control and ownership over goods and services. All three modes of sharing implicate how people interact and experience alone- and together-ness in everyday life, and relations between people and material environments. Even basic 'simultaneous' sharing is multifaceted: what counts as doing something together or 'with' somebody else is far from straightforward, encompassing a mosaic of different forms of communality. One may eat 'alone' in a crowded restaurant, watch the same television programme in separate bedrooms of the same house, 'share' a bus ride home without the music, video, book, telephone conversations of one's co-passengers, 'share' a meal time with millions of other people, and so forth. Further research might explore some of these interconnections and tensions. A hypothesis might be that people spend less time with others, partly a result of declines in household size, a lack of compensation by non-household members and that people in shared households simultaneously share less than before - exacerbating patterns of reduced sharing caused by trends towards the 'domestication' and 'privatisation' of provisioning. It may be that nonhousehold members figure more centrally in certain kinds of interactions and less so in others, that the boundaries of what is done with others have simply changed.

The household is in part defined through the sharing of practices, time and space taking place in it: changing census definitions attest to changing forms of domesticity. ${ }^{6}$ In the same way,

\footnotetext{
${ }^{6}$ In 2001 a household was defined as 'one person living alone, or a group of people (not necessarily related) living at the same address with common housekeeping - that is, sharing a living room or sitting room or at least one meal a day'. In 2011 the stipulation on shared space was emphasised over meal sharing, presumably reflecting the rise of non-familial cohabitation: 'One person living alone or a group of people (not necessarily related) living at the same address who share cooking facilities and share a living room or sitting room or dining area’ (ONS 2011: 2).
} 
anthropologist Stephen Gudeman (2001) notes, communities, cities and populations are defined by what they hold in common; meaning that studies of shifting scale and patterns of sharing do not only relate to the sustainability of their consumption, but they profoundly implicate their boundaries, governance and future.

\section{References}

Bardhi, F., and Eckhardt, G. M. (2012) 'Access-Based Consumption: The Case of Car Sharing', Journal of Consumer Research 39(4): 881-98

Belk, R. (2010). 'Sharing', Journal of Consumer Research 36(5): 715-734.

Belk, R. (2014) 'You Are What You Can Access: Sharing and Collaborative Consumption Online', Journal of Business Research 67(8): 1595-1600.

Bennett, J., and Dixon, M. (2006) 'Single Person Households and Social Policy', Joseph Rowntree Foundation Report.

Botsman, R., and Rogers, R. (2010) The Rise of Collaborative Consumption. Harper Business.

Bows, A., McLachlan, C., Mander, S., Wood, R., Roeder, M., Thornley, P., Gough, C., Thom, L. and Dawkins, E. (2012) What's Cooking: Adaptation and Mitigation in the UK Food System. Manchester: Sustainable Consumption Institute.

Cohen, M. (forthcoming) The Future of Consumer Society.

DeVault, M. (1991). Feeding the Family: The Social Organization of Caring as Gendered Work. Chicago: University of Chicago Press.

Docherty, D., Morrison, D., \& Tracey, M. (1987) The Last Picture Show? Britain's changing film audience. British Film Institute.

EST/DECC/DEFRA. (2012) Powering the Nation. Available at http://www.energysavingtrust.org.uk/Publications2/Corporate/Research-and-insights/Powering-thenation-household-electricity-using-habits-revealed. [Last accessed 18/7/14].

Euromonitor International. (2015) Washing Machine Possession. Countries and Consumers Annual Data.

Gershuny, J. (1978) After Industrial Society? The Emerging Self-Service Economy. London: Macmillan. 
Glucksmann, M. (2014). 'Bake or Buy? Comparative and Theoretical Perspectives on Divisions of Labour in Food Preparation Work'. Anthropology of Food S10.

Hall, R., Ogden, P.E. and Hill, C. (1997) 'The Pattern and Structure of One-person Households in England and Wales and France', International Journal of Population Geography 3(2): 161-81.

Heath, S., and Cleaver, E. (2004) Young, Free and Single?: Twenty-Somethings and Household Change. Basingstoke: Palgrave Macmillan.

Heinonen, J., Jalas, M., Juntunen, J.K., Ala-Mantila, S. and Junnila, S. (2013). 'Situated Lifestyles: II. The Impacts of Urban Density, Housing Type and Motorization on the Greenhouse Gas Emissions of Middle-income Consumers in Finland'. Environmental Research Letters, 8(3): 1-10.

Isaksson, C., and Ellegård, K. (2015) 'Dividing or Sharing? A Time-geographical Examination of Eating, Labour, and Energy Consumption in Sweden', Energy Research and Social Science 10: 180191.

Jarvis, H. (2015) 'Towards a Deeper Understanding of the Social Architecture of Co-housing', Urban Research \& Practice 8(1): 93-105.

Kan, M. Y., Sullivan, O., and Gershuny, J. (2011). 'Gender Convergence in Domestic Work: Discerning the Effects of Interactional and Institutional Barriers from Large-scale Data', Sociology 45(2): 234-251.

Kaufmann, J.-C. (1998) Dirty Linen: Couples and their Laundry. London: Middlesex University Press.

Klinenberg, E. (2012) Going Solo: The Extraordinary Rise and Surprising Appeal of Living Alone. New York: Penguin.

Liu, J., Daily, G. C., Ehrlich, P. R., and Luck, G. W. (2003) 'Effects of Household Dynamics on Resource Consumption and Biodiversity', Nature 421(6922): 530-3.

Mackellar, F. L., Lutz, W., Prinz, C., and Goujon, A. (1995) 'Population, Households, and CO2 Emissions', Population and Development Review 21(4): 849-865.

Molgat, M., and Vezina, M. (2008). 'Transitionless Biographies? Youth and Representations of Solo Living', Young 16(4): 349-371.

Moll, H. C., Noorman, K. J., Kok, R., Engstr, R., Throne-Holst, H., and Clark, C. (2005) 'Pursuing More Sustainable Consumption by Analyzing Household Metabolism in European Countries and Cities', Environmental Studies 9(1): 259-275.

OED. (2015) 'Share', v. http://www.oed.com/view/Entry/177535? [last accessed 13/9/15] 
ONS (2011). Chapter 3 - Households, Families and People (General Lifestyle Survey Overview 2011). Available at http://www.ons.gov.uk/ons/publications/re-reference-

tables.html?edition=tcm\%3A77-289713. [Last accessed 12/2/14]

Pahl, J. (1990) 'Household Spending, Personal Spending and the Control of Money in Marriage', Sociology 24(1): 119-138.

Schor, J.B. and Fitzmaurice, C.J., (2015) 'The Emergence of the Sharing Economy'. In L. A. Reisch \& J. Thøgersen, eds. Handbook of Research on Sustainable Consumption, pp. 410-425. Cheltenham: Edward Elgar Publishing.

Smith, A., Wasoff, F. and Jamieson, L. (2005) Solo Living across the Adult Lifecourse. CRFR Research Briefing 20.

Warde, A. (1992) 'Notes on the Relationship between Production and Consumption'. In C. Marsh (Ed.), Consumption and Class: Divisions and Change. Basingstoke: Macmillan.

Warde, A., and Martens, L. (2000) Eating Out: Social Differentiation, Consumption and Pleasure. Cambridge: Cambridge University Press.

Watson, S. (2014) 'Mundane Objects in the City: Laundry Practices and the Making and Remaking of Public/Private Sociality and Space in London and New York', Urban Studies 52(5): 876-90.

Williams, J. (2007) 'Innovative Solutions for Averting a Potential Resource Crisis-The Case of One-person Households in England and Wales'. Environment, Development and Sustainability 9(3): 325-354.

Yates, L. (2015) 'Everyday Politics, Social Practices and Movement Networks: Daily Life in Barcelona's Social Centres'. The British Journal of Sociology 66(2): 236-258.

Yates, L. and Evans, D. (2016). 'Dirtying Linen: Re-evaluating the Sustainability of Domestic Laundry.' Environmental Policy and Governance. 26(2): 101-115

Yates, L. and Warde, A. (2015) 'The Evolving Content of Meals in Great Britain'. Appetite 84: 299308.

Yates, L. (2016). 'The Environmental Threat of Small Households: Six Reasons to Think Again.' Discover Society January $5^{\text {th }}$ http://discoversociety.org/2016/01/05/the-environmental-threat-ofsmall-households-six-reasons-to-think-again/ [last accessed 17/1/16] 